\title{
ACUTE ISCHEMIC STROKE IN WOMEN: EFFICACY OF THE FREE RADICAL SCAVENGER EDARAVONE
}

10.36740/WLek202101114

\author{
Yuriy P. Vdovychenko, Oleg A. Loskutov, Oleksandr A. Halushko, Maryna A. Trishchynska, Dmytro 0. Dziuba, \\ Tetiana M. Povietkina, Alla D. Vitiuk \\ SHUPYK NATIONAL MEDICAL ACADEMY OF POSTGRADUATE EDUCATION, KYIV, UKRAINE
}

\begin{abstract}
The aim: To investigate the effectiveness of usage of the free radical scavenger Edaravone in the therapy of women with AIS.

Materials and methods: A prospective study was conducted of 48 women with AIS, divided into two groups. Patients in the first group $(n=36)$ were treated with edaravone $30 \mathrm{mg}$ twice a day intravenously. Neuroprotectors were not used in the control group $(\mathrm{n}=12)$. Clinical-instrumental and neurological examination (Glasgow scale (SCG), FOUR, NIHSS, and neuronspecific enolase (NSE) levels) were performed on all patients.

Results: The mean FOUR score in the 1 th group increased from $11.04 \pm 0.85$ to $15.47 \pm 0.63$ points against $11.39 \pm 0.56$ to $13.46 \pm 1.49$ in the control group ( $p<0.05$ ). The level of NSE in control group patients increased 10-fold (from 9.2 to $96.4 \mathrm{ng} / \mathrm{ml}, \mathrm{p}<0.01$ ). Subsequently, there was a rapid decrease in NSE level in 1th group, and in the control group until 10 days of treatment, the level of NSE did not reach the reference values $(p<0.05)$.

Conclusions: The introduction of edaravone in women with AIS results in positive results already in the acute period of the disease. The use of edaravon was significantly effective on the FOUR scale and the dynamics of NSE levels.
\end{abstract}

KEY WORDS: ischemic stroke, stroke in women, neuroprotection, edaravon

Wiad Lek. 2021;74(1):72-76

\section{INTRODUCTION}

Cardiovascular diseases (myocardial infarction, stroke, heart failure, hypertension, and cardiomyopathy) make up $40 \%$ of all causes of deaths in men and about $49 \%$ - in women [1]. Although deaths from acute ischemic stroke (AIS) have decreased in the world in recent years, it remains one of the major health problems worldwide. It should be noted that there are significant differences between the course of AIS in men and women: from the risk factors to the features of intensive care.

\section{RISK FACTORS}

Risk factors differ between men and women: for example, atrial fibrillation and hypertension are higher in women with stroke, and smoking or excessive alcohol consumption is higher in men [2]. The most significant risk factors for men are alcohol and tobacco usage, history of myocardial infarction and peripheral artery disease [3]. For women, factors associated with an increased risk of ischemic stroke are oral contraceptives, pregnancy, and menopause [4]. It has been observed that some risk factors, such as diabetes or smoking, carry a higher risk for women than for men [2].

Women-specific risk factors should be identified in a timely manner to further reduce mortality. For example, atrial fibrillation is widespread in women, requiring appropriate evaluation and prescribing of anticoagulant therapy [5]. Women with AIS and concomitant diabetes have a higher risk of cardiovascular complications and a $50 \%$ higher risk of death than men [6]. This fact requires the active detection of carbohydrate metabolism disorders in women.

\section{CLINICAL DIFFERENCES}

On average, women have a more pronounced degree of neurological impairment (in particular, higher NIHSS scores), higher mortality and disability compared to men. This is often due to the fact that they have AIS at an older age than men $[2,7]$. Interesting differences are observed in the clinical picture of the first manifestations of AIS. Women are more likely to have generalized non-specific stroke symptoms. In particular, in AIS, women are more likely to have symptoms such as disorientation, weakness, changes in mental status [8], headache, changes in consciousness [9], urinary incontinence, visual deficits, diplopia, and dysphasia [3]. On the other hand, nystagmus and sensory disorders are more common in men [8]. These differences sometimes affect the diagnosis and decision making of the treatment and transportation of patients. In addition, women are significantly older than men at the onset of AIS and are more often single or living alone, which also increases the time to be examined and hospitalized. 
Table 1. The main characteristics of patients in the study groups $(M \pm m)$

\begin{tabular}{cccc}
\hline Показник & \multicolumn{2}{c}{ Study groups } \\
\cline { 2 - 4 } & 1th group & Control group & p* \\
\hline Number of patients, $\mathrm{n}$ & 36 & $69.0[62.5 ; 73.5]$ & - \\
\hline Age, years, (Me [Q1; Q3]) & $68.5[61.75 ; 74.0]$ & $163.6 \pm 9.3$ & $>0.05$ \\
\hline Height, $\mathrm{cm}$ & $164.0 \pm 8.7$ & $73.9 \pm 8.7$ & $>0.05$ \\
\hline Weight, $\mathrm{kg}$ & $74.3 \pm 10.9$ & $27.5 \pm 3.8$ & $>0.05$ \\
\hline BMl, kg/m2 & $27.6 \pm 2.9$ & $12.9 \pm 3.7$ & $>0.05$ \\
\hline NIHSS score on admission, points & $13.4 \pm 3.1$ & $>0.05$ \\
\hline
\end{tabular}

Notes: ${ }^{*} p$ - difference of indexes relative to the comparison group; BMI - the body mass index.

\section{EXAMINATION}

Women are less likely to receive brain imaging, Doppler ultrasound, echocardiography, and angiography than men of the same age [3].

\section{DIFFERENCES IN TREATMENT}

Surgical treatment of AIS, in particular carotene treatments, is quite popular in high-risk patients. However, carotid endarterectomy is performed less in women than in men, even after adjusting for age and comorbidity. This is due to the higher perioperative risk in women [10] and to the fact that carotid diseases are more common in men. In addition, the main method of treatment for AIS is the introduction of recombinant tissue plasminogen activator (rt-PA) and it also less commonly used in women than in men. The main reasons for this are late hospitalization and the presence of more comorbid pathology [4].

Thus, all of the listed features of AIS in women significantly reduce the ability to receive appropriate and timely care, and ultimately impair treatment outcomes. All of this requires finding other ways to help women with AIS. Medicinal neuroprotection is such therapy that reduces damage, prevents neuronal death at the cellular and molecular levels, or promotes brain cell recovery after acute ischemia or reperfusion [11].

One of the most interesting and promising drugs in the group of neuroprotectors is edaravon, a low molecular weight antioxidant agent that interacts deliberately with peroxyl radicals [12]. Free radicals are one of the main causes of ischemia-related vascular disorders in the brain. They cause the peroxidation of unsaturated fatty acids, which are part of the cell membrane lipids, damages them, which leads to impaired brain function. Edaravon inhibits lipid oxidation by absorbing water-soluble peroxyl radicals that initiate chain reactions, and absorbs fat-soluble peroxyl radicals supporting the chain. In the acute stage of AIS, the drug exhibits a protective effect by suppressing the onset and development of ischemic cerebrovascular disorders such as brain swelling, neurological symptoms, slow neuronal death. This is the way in which edaravon inhibits the early and late stages of the ischemic process and prevents reperfusion injury in AIS [12].

Edaravon was developed and implemented by Japanese company Mitsubishi Tanabe Pharma in 2001. Since then,
Edaravon has been successfully prescribed in Japan for the treatment of AIS, and for many years it has been included in the Japanese National AIS Guideline (recommendation level B) [13]. To date, the efficacy and safety of edaravon in the treatment of ischemic stroke has been demonstrated in many clinical studies $[14,15,16]$. However, there is insufficient data on the use of edaravone in the cohort of women undergoing AIS. This led to the need for this study.

\section{THE AIM}

The aim of this study is to investigate the effectiveness of usage of the free radical scavenger Edaravone in the therapy of women with acute ischemic stroke.

\section{MATERIALS AND METHODS}

To achieve the goal of the study, a prospective comprehensive clinical and neurological and laboratory examination was conducted. 48 patients with acute ischemic stroke were examined. The study was conducted at the intensive care unit of the Kyiv Region Clinical Hospital from September 2018 to August 2019. Prior to the start of the study, patients signed an informed consent. The protocol and the study program were approved by the Shupyk NMAPE Ethics Committee.

The criterion for involvement in the study was: acute ischemic stroke, verified by clinical neurological and neuroimaging methods.

The criterions for exclusion from the study were the presence of a patient with severe comorbid pathology: acute myocardial infarction, acute renal, hepatic and respiratory failure, epilepsy, brain tumor, hemorrhagic stroke.

The patients were divided into two groups. To a patients of the first group $(n=36)$ was prescribed a solution containing $1.5 \mathrm{mg}$ of edaravone in $1 \mathrm{ml}$ solution at a dose of 30 mg of edaravone ( 1 ampoule) twice daily, in the morning and in the evening, by intravenous infusion for 30 minutes. Prior to administration, the contents of the ampoule was dissolved in $100 \mathrm{ml}$ of $0.9 \%$ sodium chloride solution. The drug was in the form of intravenous drip (40-60 drops per minute). In the control group ( $\mathrm{n}=12$ patients) drugs with the claimed neuroprotective effect were not used. The patients of the presented groups did not differ in basic 
Table 2. Results of scores on the FOUR scale, points $(M \pm m)$

\begin{tabular}{ccccccc}
\hline \multirow{2}{*}{ Parameters } & \multicolumn{6}{c}{ Study days } \\
\cline { 2 - 7 } & $\mathbf{1}$ & $\mathbf{3}$ & $\mathbf{5}$ & $\mathbf{7}$ & $\mathbf{9}$ & $\mathbf{1 0}$ \\
\hline The first group $(\mathrm{n}=36)$ & $11.04 \pm 0.85$ & $12.15 \pm 0.91$ & $13.29 \pm 1.09$ & $13.98 \pm 1.38$ & $15.04 \pm 1.16$ & $15.47 \pm 0.63$ \\
\hline Control group $(\mathrm{n}=12)$ & $11.39 \pm 0.56$ & $11.64 \pm 1.22$ & $12.37 \pm 1.73$ & $12.64 \pm 1.82$ & $13.38 \pm 1.53$ & $13.46 \pm 1.49$ \\
\hline Intergroup differences $(\mathrm{p})$ & $>0.05$ & $>0.05$ & $>0.05$ & $>0.05$ & $<0.05^{*}$ & $<0.05^{*}$ \\
\hline
\end{tabular}

Note: ${ }^{*}$ - the differences are statistically significant $(p<0.05)$.

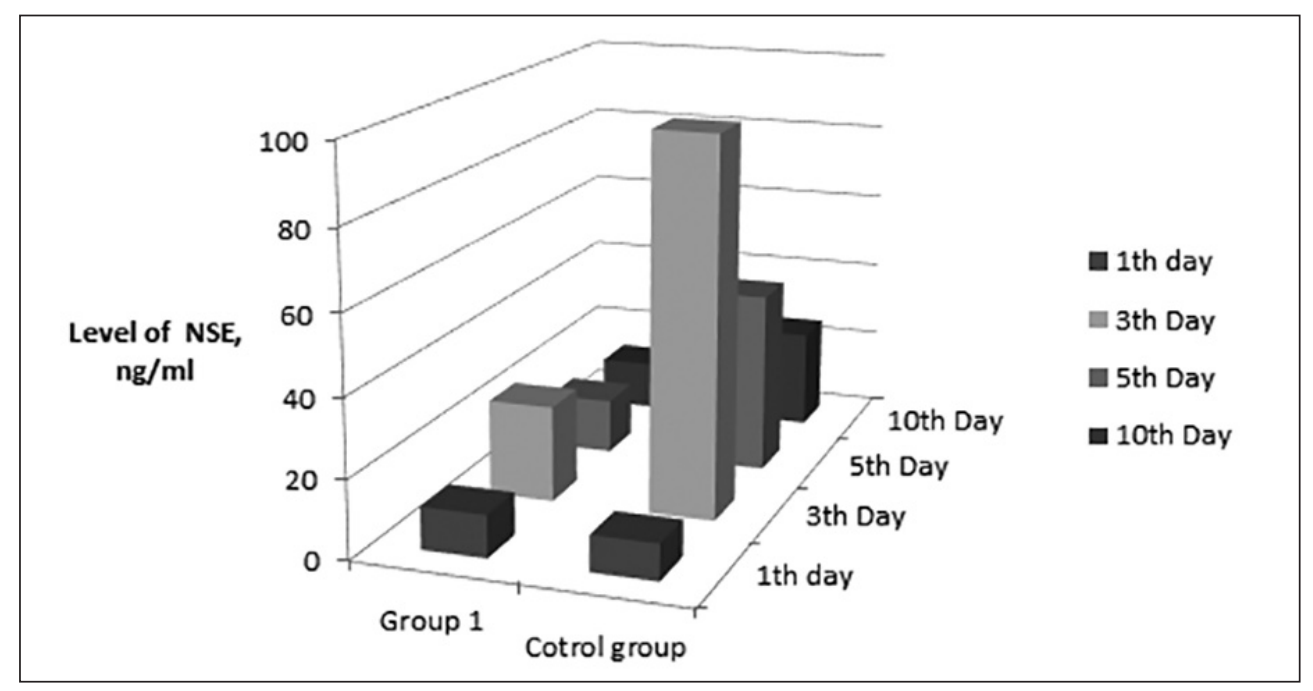

Fig. 1. The dynamics of NSE changes.

anthropometric, anamnestic and clinical-instrumental characteristics, which is shown in Table I.

Examination of patients included clinical and laboratory monitoring of biochemical and coagulatory parameters of blood and urine, comprehensive instrumental examination. Diagnosis of AIS and its localization were verified by computed tomography (CT) and / or magnetic resonance imaging (MRI) of the brain. The following parameters were used as the criteria for the effectiveness of cerebroprotective therapy: assessment of Glasgow Coma Scale (GCS) and FOUR scale, NIHSS score (stroke severity) and Bartel index (daily activity score); the level of neurospecific enolase (NSE; marker of neuronal damage); cerebral oximetry (rSO2; marker of brain oxygenation). These parameters were determined in patients throughout the treatment period, at the end of treatment, a control neuroimaging study (CT or MRI) was performed.

Statistical processing of the results was carried out using statistical analysis packages Microsoft Excel 2010 and SPSS 13.0 using non-parametric methods. The probability of difference between the average quantitative values of the two samples was determined by the Student's t-test. For all parameters measured the average $(\mathrm{M})$, the average error (m). Pearson's $\chi^{2}$ criterion was used to estimate the likelihood of differences between several relative values.

\section{RESULTS}

In the subtype of stroke, patients with large artery atherosclerosis predominated in both groups (group $1-25$ patients (69.4\%), control group - 8 patients (66.7\%), p>
0.05). Lacunar strokes were diagnosed: group 1 in 6 patients (16.7\%), control group - in 3 patients (25.0\%), p > 0.05 . Cardioembolic strokes were diagnosed: 1 th group -5 patients (13.9\%), control group - 1 patient (8.33\%), $\mathrm{p}>0.05$.

Analysis of GCS estimates showed the presence of positive dynamics in the majority of patients in both groups, with no significant statistical difference $(p>0.05)$ between the groups. Thus, the mean GCS score in the main group increased from $11.84 \pm 2.62$ to $13.87 \pm 0.94$ points against $11.69 \pm 3.15$ to $13.31 \pm 1.78$ in the control group ( $p>0,05)$. However, not all women were diagnosed by the Glasgow coma scale (presence of an intubation tube, motor aphasia), so patients' consciousness was evaluated by the FOUR scale (Table II). In the group where the free radical scavenger edaravon was used (1th group), the level of consciousness recovered more rapidly (since the 5th day) than in the control group. According to the analysis of the FOUR scale, within 9-10 days of treatment, the difference between the scores became significant and reached the level of statistical significance: in the edaravon group - $15.47 \pm 0.63$ points, in the control group $-13.46 \pm 1.19$ points $(\mathrm{p}<0.05)$.

In the analysis of the dynamics of the assessment of stroke severity on the NIHSS scale it was found that patients had predominantly AIS moderate severity (within $10-12$ points on the NIHSS), during treatment the number of points gradually decreased without statistical difference between the main and control groups of the study ( $\mathrm{p}>0.05)$.

Analyzing the dynamics of NSE changes, the following results were obtained. On the 3 rd day of treatment in both groups, the level of NSE exceeded the normal values, and most of all - in patients of the control group the level of NSE 
increased 10 times (from 9.2 to $96.4 \mathrm{ng} / \mathrm{ml}$ ). In group 1, increas in NSE was also observed, but with a much lesser extent (from 10.8 to $24.6 \mathrm{ng} / \mathrm{ml}, \mathrm{p}<0.05$ between groups). Subsequently, there was a rapid decrease of the level of NSE, which in the first group reached normal levels by the 10th day of treatment. In the control group, the dynamics of NSE decrease were not so pronounced and by 10 days of treatment the NSE level did not reach the reference values (Fig. 1).

When evaluating the indicators of cerebral oximetry ( $\mathrm{rSO} 2)$, it was found that in patients of different age groups and comorbid conditions, this indicator can vary significantly - from 65 to $90 \%$, and in the case of AIS, the indicator $\mathrm{rSO} 2$ over the affected hemisphere. In the course of the study it was noted that patients of the control group experienced a sharp decrease in $\mathrm{rSO} 2$ (especially for 3-4 days), followed by a long and slow increase. In patients treated with edaravone, a decrease in $\mathrm{rSO} 2$ was less pronounced and less durable, although the difference between study groups was not statistically significant $(p>0.05)$.

\section{DISCUSSION}

As noted, the efficacy of edaravone in the treatment of AIS has been shown in many studies. Thus, according to a Phase III study, when using edaravone in patients with acute ischemic stroke, it was found that in the assessment of functional status on the Rankin scale 3 months after stroke development, a complete absence of functional disorders was noted in 27 of 125 patients (21.6\%) against 12 of 125 (9.6\%) in patients in the placebo group [17]. It has been reported that, with concomitant use of edaravone with endovascular therapy, better neurological results were observed at hospital discharge [18].

At the same time, information on the efficacy of edaravone mainly relates to long-term treatment outcomes [19]. And our study reflects the effects of edaravone which are developed during the acute period of AIS - the first days and hours of the onset of symptoms.

The dynamics of neurological status assessments that was observed in our study indicate the efficacy of edaravone in the acute period of AIS. Positive treatment outcomes were achieved in all patient groups. However, women receiving edaravone had a more pronounced improvement in neurological symptoms than women of the control group. However, a statistically significant difference was observed only in the dynamics of NSE levels and FOUR scores. We believe that the validity of the positive effect of edaravon on major neurological outcomes in stroke will be fully validated in further randomized trials.

\section{CONCLUSIONS}

1. The usage of edaravone in women with AIS leads to positive results already in the acute period of the disease.

2. In particular, the usage of edaravone was significantly effective in terms of neurological status (level of consciousness on the FOUR scale) and the dynamics of levels of neurological markers (NSE).
3. Further studies are needed to clarify the role and location of edaravone in the ischemic stroke intensive care setting.

\section{REFERENCES}

1. Tomaszewski M., Topyła W., Kijewski B.G. et al. Does gender influence the outcome of ischemic heart disease? Prz Menopauzalny. 2019;18(1):51-56.

2. Christensen H., Bentsen L., Christensen L. Update on specificities of stroke in women. Presse Med. 2016; 45(12): e409-e418.

3. Di Carlo A., Lamassa M., Baldereschi M. et al. Sex differences in the clinical presentation, resource use, and 3-month outcome of acute stroke in Europe: Data from a multicenter multinational hospital-based registry. Stroke. 2003; 34: 1114-1119.

4. Girijala R.L., Sohrabji F., Bush R.L. Sex differences in stroke: Review of current knowledge and evidence. Vasc Med. 2017;22(2):135-145. doi: $10.1177 / 1358863 \times 16668263$.

5. Lundberg G.P., Volgman A.S. Burden of stroke in women. Trends Cardiovasc Med. 2016;26(1):81-88.

6. Triches C., Schaan B.D., Gross J.L. et al. Macrovascular diabetic complications: clinical characteristics, diagnosis and management. Arq Bras Endocrinol Metabol. 2009;53(6): 698-708.

7. Appelros P., Stegmayr B., Terént A. Sex differences in stroke epidemiology: a systematic review. Stroke. 2009;40(4):1082-90.

8. Jerath N.U., Reddy C., Freeman W.D. et al. Gender differences in presenting signs and symptoms of acute ischemic stroke: A populationbased study. Gend Med. 2011; 8: 312-319.

9. Labiche L.A., Chan W., Saldin K.R. et al. Sex and acute stroke presentation. Ann Emerg Med. 2002; 40: 453-460.

10. Alamowitch S., Eliasziw M., Barnett H.J. et al. The risk and benefit of endarterectomy in women with symptomatic internal carotid artery disease. Stroke. 2005; 36: 27-31.

11. Moretti A., Ferrari F., Villa R.F. Neuroprotection for ischaemic stroke: current status and challenges. Pharmacol Ther. 2015;146: 23-34.

12. Watanabe K., Tanaka M., Yuki S. et al. How is edaravone effective against acute ischemic stroke and amyotrophic lateral sclerosis? I Clin Biochem Nutr. 2018;62(1):20-38. doi: 10.3164/jcbn.17-62.

13. Kern R., Nagayama M., Toyoda K. et al. Comparison of the European and Japanese guidelines for the management of ischemic stroke. Cerebrovasc Dis. 2013;35(5): 402-418.

14. Kaste M., Murayama S., Ford G.A. et al. Safety, tolerability and pharmacokinetics of MCl-186 in patients with acute ischemic stroke: new formulation and dosing regimen. Cerebrovasc Dis. 2013: 36: 196-204.

15. Yamaguchi T., Awano H., Matsuda H. et al. Edaravone with and without $.6 \mathrm{Mg} / \mathrm{Kg}$ Alteplase within 4.5 Hours after Ischemic Stroke: A Prospective Cohort Study (PROTECT4.5). J Stroke Cerebrovasc Dis. 2017;26(4):756765. doi: 10.1016/j.jstrokecerebrovasdis.2016.10.011.

16. Yang J., Cui X., Li J. et al. Edaravone for acute stroke: Meta-analyses of data from randomized controlled trials. Dev Neurorehabil. 2015;18(5):330-5. doi: 10.3109/17518423.2013.830153.

17. Edaravone Acute Infarction Study Group. Effect of a novel free radical scavenger, edaravone (MCI-186), on acute brain infarction. Randomized, placebo-controlled, double-blind study at multicenters. Cerebrovasc Dis. 2003; 15(3):222-229.

18. Enomoto M., Endo A., Yatsushige H. et al. Clinical Effects of Early Edaravone Use in Acute Ischemic Stroke Patients Treated by Endovascular Reperfusion Therapy. Stroke. 2019;50(3):652-658. doi: 10.1161/STROKEAHA.118.023815. 
19. Manwani B., McCullough L.D. On the Basis of Sex. Outcomes After Ischemic Stroke. Stroke. 2019;50(9):2285-2287. doi: 10.1161/ STROKEAHA.119.025955.

\section{ORCID and contributionship:}

Yuriy P. Vdovychenko: 0000-0001-5768-0973 ${ }^{A, B}$

Oleg A. Loskutov: 0000-0002-3595-5611 B,C

Oleksandr A. Halushko: 0000-0001-7027-8110 A,F

Maryna A. Trishchynska: 0000-0002-1022-0635 ${ }^{C, D}$

Dmytro O. Dziuba: 0000-0002-9979-8889 D,E

Tetiana M. Povietkina: 0000-0002-9442-2188 C,E

Alla D. Vitiuk: 0000-0003-0550-7196 C,F

\section{Conflict of interest:}

The Authors declare no conflict of interest.

\section{CORRESPONDING AUTHOR}

\section{Oleksandr A. Halushko}

Shupyk National Medical Academy of Postgraduate Education 9 Dorogozhytska St., 04112 Kyiv, Ukraine

tel: +380954815577

e-mail: o.halushko@ukr.net

Received: 07.03 .2020

Accepted: 12.10 .2020

A - Work concept and design, B - Data collection and analysis, C - Responsibility for statistical analysis,

D-Writing the article, $\mathbf{E}$-Critical review, $\mathbf{F}$ - Final approval of the article 